\title{
Food Contamination: A Primer
}

\author{
Matthew N. O. Sadiku', Tolulope J. Ashaolu², and Sarhan M. Musa ${ }^{1}$ \\ ${ }^{1}$ Roy G. Perry College of Engineering \\ Prairie View A\&M University, US \\ ${ }^{2}$ College of Food Science \\ Southwest University, Tiansheng Road Beibei District, \\ Chongqing, 400715, P.R. China
}

\begin{abstract}
Food is regarded as hygienic and safe for consumption when it does not pose any threat or risk to the health and economy such as sales loss. Food contamination occurs when bacteria or other germs get into food, which can cause food-borne illness. While most food contaminations are accidental, there has been some evidence of intentional food contamination. A major accident in food contamination can cost a company a massive recall that may be devastating to its reputation and profit because it has serious consequences for the health and wellbeing of people and the planet. This paper aims at providing a primer on food contamination, its causes, and prevention.
\end{abstract}

Key Words: Food Contamination, Contaminant, Food-Borne Illness.

\section{INTRODUCTION}

Food greatly contributes to human well-being and is a major source of anxiety, pleasures, and stress. Food is regarded safe and hygienic when there is no dangerous substance that can be injurious to health. Foods and drinks can be contaminated, thereby becoming inappropriate for consumption. Food contamination, either from microbiological or chemical origin, is a major concern for consumers. It can cause catastrophic health and economic effects. Food-borne illnesses cause major international health problems and reduced economic growth. Food contamination incidents, whether intentional or unintentional, can have dire consequences for both the customer who eats it and the business who sold it.

\section{CONCEPT OF FOOD CONTAMINATION}

Food contamination occurs when bacteria or other germs get into food that should not be there, thereby making the food unsafe for consumption. It may also be regarded as foods that are spoiled because they contain microorganisms that make them unfit for consumption. Figure 1 shows some highly contaminated foods [1]. Food safety is compromised when foodstuffs get contaminated with a potentially hazardous agent [2].

As shown in Figure 2, contamination of food during processing is divided into three categories: biological, chemical, and physical or foreign material $[3,4]$.

- Biological Contamination: This occurs when bacteria, fungal, or other harmful microorganisms contaminate food. It is a common cause of food poisoning, food spoilage, and food-borne illness. Although all foods can harbor dangerous pathogens, some foods are more vulnerable to biological contamination than others.

- Chemical Contamination: This refers to food that has been contaminated by some type of chemical substance. Common sources of chemical contamination include agrochemicals, kitchen equipment, unwashed fruits and vegetables, and food containers made from non-safe plastics. Nuclear accidents can lead to widespread environmental contamination and cause death.

- Physical Contamination: This takes place when physical objects enter food. Common sources of physical contamination include metals, glass, hair, fingernails, pests, jewelry, and dirt. 
There are two types of contaminants: (1) natural contaminants, which are unintentionally present in food, (2) those introduced intentionally such as food additives, veterinary drugs, and pesticides. The release of pollutants into the environment increases metal concentrations, which contaminate the food supply [5]. In the food processing industry, food and food contact surfaces can become contaminated with microorganisms through contact with soil, water, fertilizers, equipment, humans, and animals. The presence of material on a surface affects its hygiene status and cleanability. Stainless steel remains the surface of choice in most cases in the food industry [6].

\section{SOURCES OF FOOD CONTAMINATION}

Food contaminant may be regarded as every substance not intentionally added to the food, but found inside the food during the production process, farming practices, treatment, packaging, transport, storage of food, or from environmental sources [7]. Thus, food contamination can take place at different steps of the food process food, from the reception of raw materials to the final food intake by consumers. The sources involved in the food contamination processes include (a) External raw food contamination due to environmental contamination; (b) Transport of raw materials to the factory where they will be processed; (c) Food conditioning, which involves the storage of raw materials, preheating, disinfection, cleaning and sterilization steps; (d) Heating steps either by boiling, cooking, baking, frying or combining with other ingredients at high temperature in an oven or in a reactor; e) Food packaging; (f) Transport of packaged food and g) Storage and distribution of packaged food [8]. Figure 3 shows potential contamination of food by humans [9]. These food contamination sources are further explained as follows [8-10]:

- $\quad$ Contamination in food processing chain: It takes several steps to get food from the farm to the dining table and these steps are known as the food processing chain. The supply chain is illustrated in Figure 4 [11]. Metal contamination can occur during handling and processing of foods, from the farm to the consumer. Processing contaminants are produced during the processing of foods (e.g., heating, fermentation).

- $\quad$ Contamination during food transport: Food contamination can take place during its transportation. Common sources of contamination include the vehicle exhausts of diesel and petrol or cross-contamination in the vehicle.

- $\quad$ Contamination caused by cleaning processes: Cleaning and disinfecting during food processing are crucial to reduce food contamination. Hygiene and food contact stainless steel surfaces cleanliness are critical for food quality and safety.

- Contamination during food preparation: Preparation is getting the food ready to eat. Foods are likely to be contaminated during preparation or dissemination by the food handler. Poor personal hygiene by food handlers often contributes to outbreaks of food borne illnesses.

- Contamination in food restaurant: Local authorities should guarantee that the food sold to consumers in fast food restaurants is safe, wholesome and fit for human consumption in order to avoid outbreaks of food-borne illnesses.

Contamination during food storage: Proper storage is meant to extend the shelf life of food. Absorption of unwanted off-odors is common in food storage. Some of the contaminating factors include direct sunlight that speeds deterioration of food and adsorption of unwanted off-odors.

- Contamination in food packaging: Packaging can be a source of contamination due to migration phenomena of packaging to food. Packaging processes make use of several additives to improve the packaging materials. Any direct or indirect contact with the packaged food can result in the transference of these substances from the packaging into the food.

- $\quad$ Contamination by metals: Contact between food and metal (such as from processing equipment) is a significant source of metal in food. Lead in food originates mainly from atmospheric deposition and from drinking water In regions where lead water pipes are used. Mercury (inorganic and organic) is found in food.

- $\quad$ Contamination by chemicals: Chemical contaminants may occur in our food and drinking water from various sources. Contaminants can be present in foods due to the use of agrochemicals. Contamination can also be due to natural toxins or use of unapproved food additives. Undesirable chemicals can enter foodstuffs during growth and processing.

- Contamination from environmental sources: We may also have environmental contaminants, which are chemicals from the environment in which the food is grown, harvested, transported, stored, packaged, processed, and consumed. Mercury is a naturally occurring element that is released to the environment from the combustion of coal. Children may be at a greater risk for exposures to environmental contaminants.

\section{PREVENTING FOOD CONTAMINATION}

Knowing how food can be contaminated, you can now take steps to prevent it. The rapid and reliable detection methods of chemical contaminants are important in managing the safety of food. Everyone who works with food has a legal responsibility to take all reasonable measures to protect the public from health risks like food-borne illness and food allergies. The best way to 
prevent food contamination is through education and training [12]. You can do this as individuals handing food or a food business. The availability of fast, reliable, and simple detecting tools for food commodities is a target both for customer and food business. As technology advances, the detection of food contaminants becomes easier.

- Individual Consumers: To prevent food contamination, you need to follow food safety best practices designed to control bacterial growth through proper food handling techniques, rigorous cleaning and sanitizing procedures.

- Business Entities: Preventing food contamination at the business level is important because your income is directly tied to the success of your business. To minimize the risk of biological food contamination occurring in your food business, you need to provide proper training to food handlers. Food Handlers must be trained in fundamental food safety concepts and practical skills, such as safe cooking temperatures, proper storage and preparation of high-risk foods (also called 'potentially hazardous foods'), effective cleaning and sanitizing techniques, properly wash fruits and vegetables to remove pesticides, maintain good personal hygiene [3]. Improved means for growing, harvesting, processing, and storing the food crops help prevent contamination. Radiation of foods can kill germs in food products.

- Contamination Detection: Various reliable techniques, such as polymerase chain reaction (PCR) and enzyme linked immunosorbent assay (ELISA) are available for the detection of pathogens present in food products. Rapid detection of food-borne volatile organic compounds (VOCs) is being used as an intelligent indicator for detecting bacterial contamination in food. Timely detection of the food-borne pathogens can assist in preventing the spread of diseases [13]. The food processing industry depends on spot checks during manufacture and random sampling of final products to ensure safe foods.

- Food Inspection/Regulation: In the US, the Food and Drug Administration (FDA) an US Department of Agriculture (USDA) are the government agencies responsible for food safety. While FDA creates regulations for companies to follow when producing food products, USDA promotes food safety by reducing the amount of food hazards found in food from the farm to the table. The FDA has given a set of standards to determine whether food contamination should result in a recall. The Centre for Disease Control and Prevention (CDC) track food-borne illnesses and outbreaks in order to develop control measures [14]. According to CDC, approximately 48 million Americans get sick from food borne illnesses every year. Disease causing pathogens in foods can be reduced through better farm practices and food regulations.

\section{GLOBAL IMPLICATIONS}

In today's connected world, it is crucial to understand the global implications of food contamination. Although food contamination may occur in one place, it may affect the health of consumers living on the other side of the planet. In the current world of instant global new coverage, the media's influence on consumer perception of food safety, food recall can damage a company's reputation.

The United States imports about $20 \%$ of its food and each exporting nation has different food safety standards. The US Food and Drug Administration (FDA) has opened offices in several cities outside the US (such as Beijing) that will examine food exports destined for the United States. The government agency determines the safety of foods. A number of suspect foods from China tested by the FDA were found to contain melamine. The World Health Organization (WHO) has recognized food contamination as a major global challenge. The organization is trying hard to develop useful recommendations.

\section{BENEFITS AND CHALLENGES}

Food contamination is a serious issue that affects the global community. Customers rely on the fact that the food system is reliable and resilient. Food contamination puts customers at risk and can be detrimental to the economy. It has a major impact on the public health. When a person develops symptoms due to food contamination, they seek care from a healthcare professional [15]. Prevention of food contamination helps in the preservation of public health. Ensuring the supply of safe food products is important to protect public health and the food industry

Protecting the general public from the danger of contaminated foods has become an uphill task. Food contamination is a main cause educated consumers complain against manufacturers, resulting in loss of brand loyalty. Food-borne illness is a giant, expensive challenge for big or small food companies because it has serious consequences for the health and wellbeing of people and planet. The early detection of agricultural food crop contamination poses a challenging task. The task of identifying the contaminants, weather coming from the food production, or food processing or the packaging, is still a challenge. Contaminated 
meat and poultry (beef, chicken, pork, ham, turkey, etc.) still pose a health threat to the United States. In developing countries like Ghana in West Africa, the incidence of microbial food contamination is common. This may be due to commercial food operations, specifically street foods [16].

\section{CONCLUSION}

Food contamination is a serious public health problem worldwide. Foods can be contaminated during the entire life of a food product. Good agricultural practices and good manufacturing practices represent the primary line of defense against contamination of foodstuffs. Each national government is responsible to ensure that food products do not contain contaminants. National authorities should educate producers regarding the environmental factors that promote infection, growth and toxin production in crops and good manufacturing practices during the handling, storage, processing, and distribution of cereals for human food and animal feed [7].

Due to the global implications, it is vital for food business and food consumers to understand the nature of contamination, its sources, risks to the consumer, and methods to eliminate or reduce it Special attention should be given to the preparation, storage, and service of food such as salad, which is one of the most commonly contaminated foods [17]. Food handlers must be trained to handle food safely, practice personal hygiene, and prevent contamination. More information about food contamination can be found in the books in $[9,18,19]$ and related journals:

- Foods

- Food Additives \& Contaminants

- British Food Journal

- Journal of Food Studies

- $\quad$ Trends in Food Science \& Technology

\section{REFERENCES}

[1] "Top 9 highly contaminated foods," https://optimalhealthsolutions.ca/top-9-highly-contaminated-foods/

[2] M. A. Hussain, "Food contamination: major challenges of the future," Foods, vol. 5, 2016.

[3] "Soil health," https://www.ndsu.edu/soilhealth/?page_id=37

[4] "Food safety and the different types of food contamination,"

https://www.foodsafety.com.au/resources/articles/food-safety-and-the-different-types-of-food-contamination

[5] L. Nasreddine and D. Parent-Massin. "Food contamination by metals and pesticides in the European Union. Should we worry?" Toxicology Letters, vol. 127, no. 1-3, February 2002, pp.29-41.

[6] J. Verran et al., "Chapter 8 Microbial retention on open food contact surfaces and implications for food contamination," Advances in Applied Microbiology, vol. 64, 2008, pp. 223-246.

[7] V. D. Stefano and G. Avellone, "Food contaminants," Journal of Food Studies, vol. 3, no. 1, 2014, pp. 88-103.

[8] C. Nerín,and M. Aznar,and D. Carrizo, "Food contamination during food process," Trends in Food Science \& Technology, vol.48, February 2016, pp. 63-68.

[9] "Food contamination sources," in N. G. Marriott and R. B. Gravani, Principles of Food Sanitation. New York, NY: Springer, 5th Edition, Chapter 5, 2006.

[10] "Food contaminant," Wikipedia, the free encyclopedia

https://en.wikipedia.org/wiki/Food_contaminant

[11] R. T. Teasley, "Are we sick yet: Assessing consumer mortality from food contamination in multiple distribution channels," Master's Thesis, North Carolina A\&T State University, 2013.

[12] "Food safety and the types of food contamination," May 16, 2019

https://www.foodsafety.com.au/resources/articles/food-safety-and-the-different-types-of-food-contamination

[13] S. Sankaran, "Development and evaluation of novel sensing materials for detecting food contamination," Doctoral Dissertation, North Dakota State University of Agriculture and Applied Science, July 2009.

[14] J. B. Talley, "Modeling individual consumer food contamination progression with interventions," Doctoral Dissertation, North Carolina A\&T State University, 2016.

[15] J. R. Ingelfinger, "Melamine and the global implications of food contamination,"

New England Journal of Medicine, vol. 359, December 2008, pp. 2745-2748.

[16] E. Yeleliere, S. J. Cobbina, and Z. I. Abubakari, "Review of microbial food contamination and food hygiene in selected capital cities of Ghana," Cogent Food \& Agriculture, vol. 3, no. 1, 2017.

[17] ,E .C. Isah, P. V. O. Lofor, and C. K. Ojide, "Food contamination in fast food restaurants in Benin City, Edo State, Nigeria: Implications for food hygiene and safety," 
Public Health, vol. 124, no. 8August 2010, pp. 467-471.

[18] A. H. Kimura, Radiation Brain Moms and Citizen Scientists: The Gender Politics of Food Contamination after Fukushima. Durham, NC: Duke University Press, 2016.

[19] C. L. Wilson and S. Droby, Microbial Food Contamination. Boca Raton, FL: CRC Pess, 2001.

\section{ABOUT THE AUTHORS}

Matthew N.O. Sadiku is a professor in the Department of Electrical and Computer Engineering at Prairie View A\&M University, Prairie View, Texas. He is the author of several books and papers. His areas of research interests include computational electromagnetics and computer networks. He is a fellow of IEEE.

Tolulope J. Ashaolu is a research fellow at Southwest University, Chongqing, China. He is the author of several papers and two books. His research interests include functional foods and food microbiology.

Sarhan M. Musa is a professor in the Department of Electrical and Computer Engineering at Prairie View A\&M University, Texas. He has been the director of Prairie View Networking Academy, Texas, since 2004. He is an LTD Sprint and Boeing Welliver Fellow. His research interests include computer networks and computational electromagnetics.

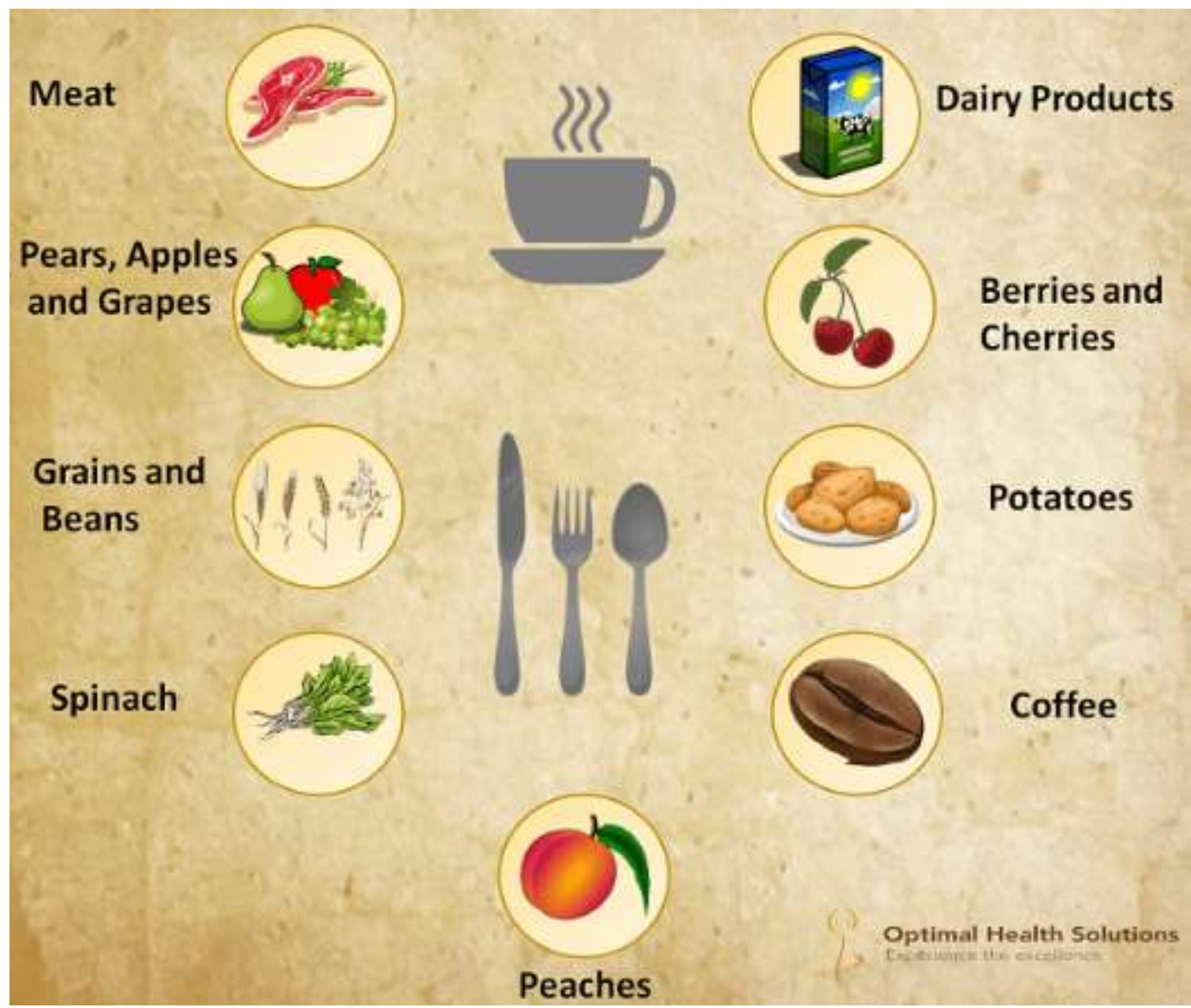

Figure 1 Top highly contaminated foods [1]. 


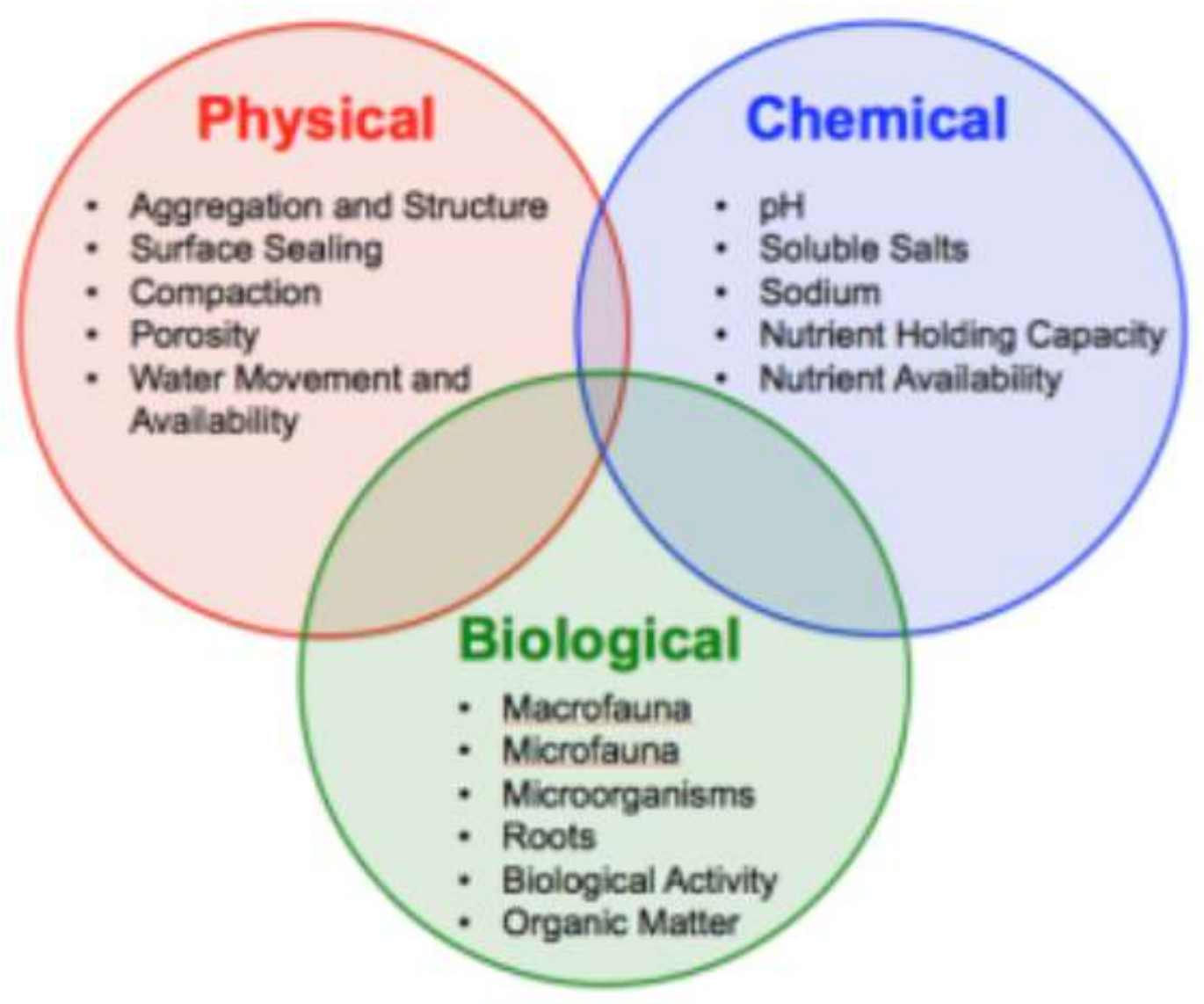

Figure 2 Types of food contaminants [3].

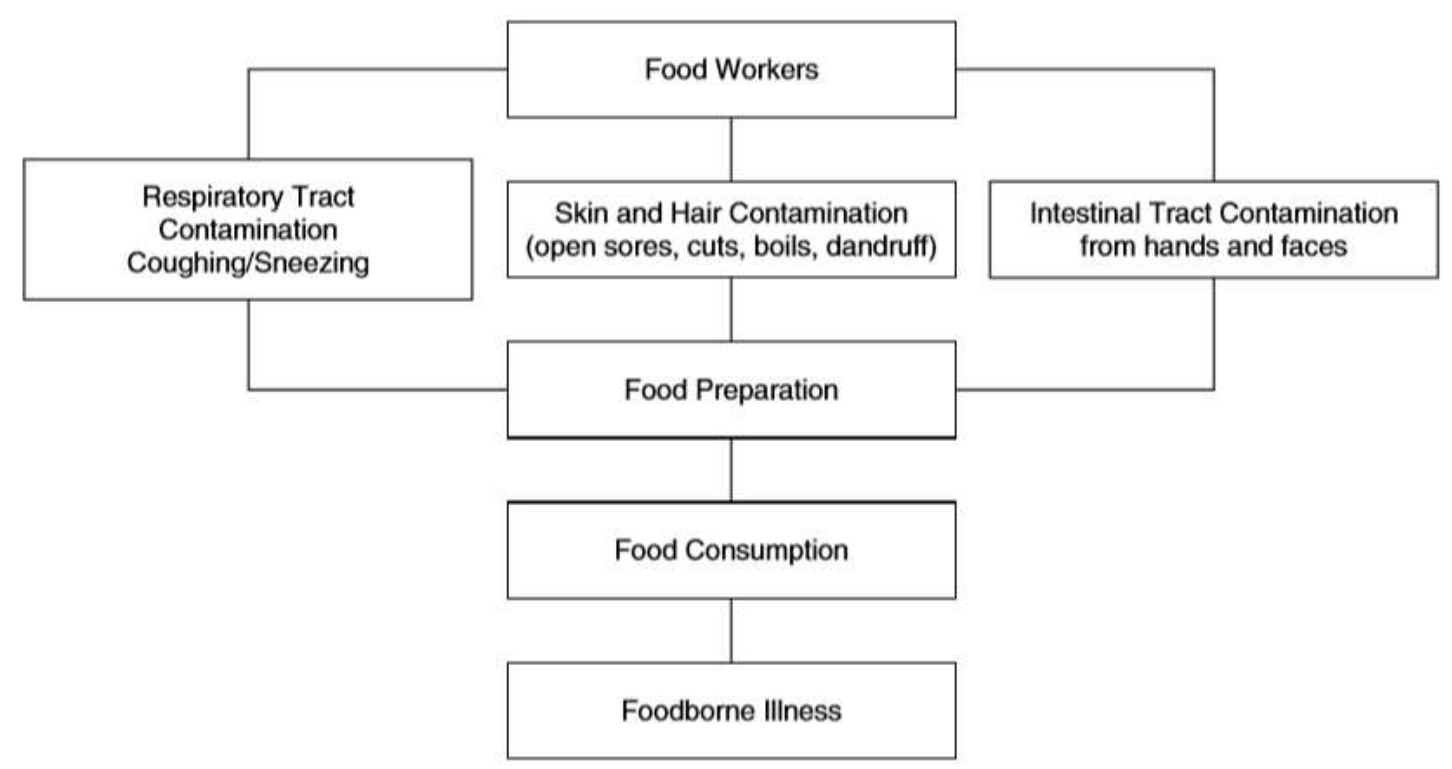

Figure 3 Potential contamination of food by humans [9]. 
International Journal of Advances in Scientific Research and Engineering (ijasre), Vol 6 (3), March -2020

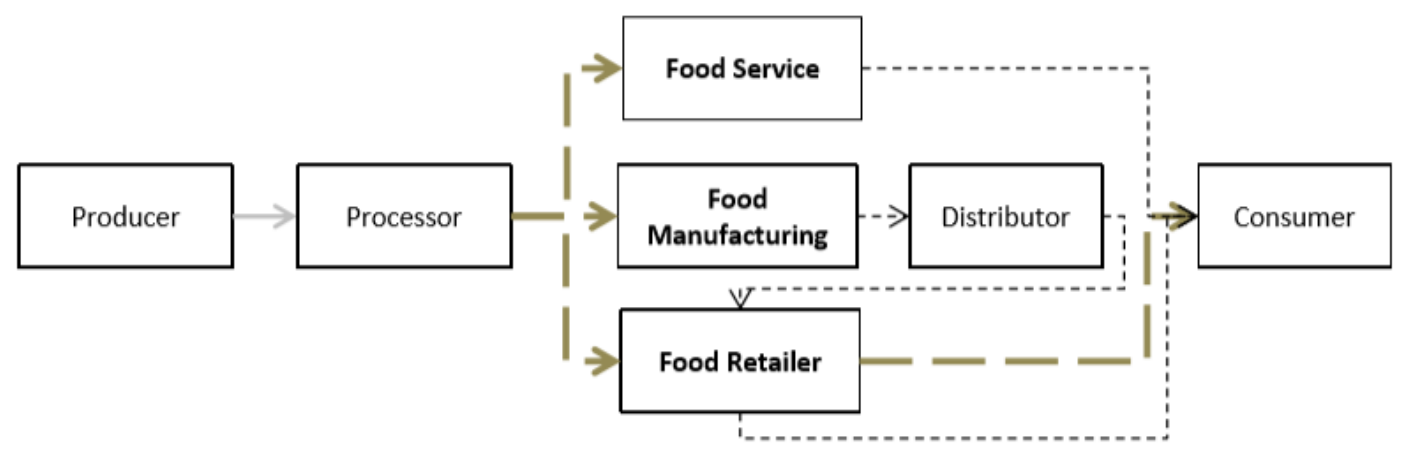

Figure 4 Supply chain distribution channels [11]. 